\title{
Universal dental syringe launched
}

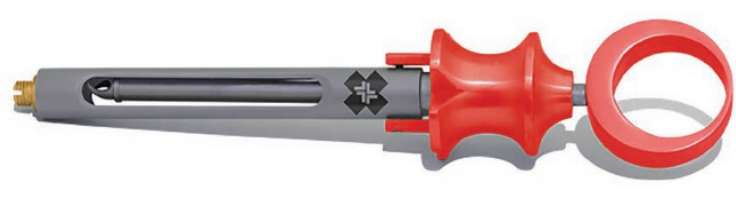

range, the syringe also comes in six different colours. This enables differentiation, for example in multiple practices.

ISFY International's Anaqa range of instruments features the finest

Surgical instruments manufacturer, ISFY International, has launched an innovative, universal dental syringe that is practical, versatile and user friendly.

The syringe is the first on the market that is compatible with both $1.8 \mathrm{ml}$ and $2.2 \mathrm{ml}$ vials, eliminating the need to use separate syringes on adults and children. It also has interchangeable threads that can accommodate all types of disposable needle, which makes it truly universal.

A removable silicone insert in the handle improves grip and makes it easier to use for dentists with smaller hands.

Part of the brand's premium Anaqa

\section{Building on a year of brilliance}

The BDIA Dental Showcase 2016 was a particularly victorious event for Curaprox, not least because of the amount of interest received from the busy crowds that flocked to the stand.

As ever, the stars of the show were the ultra-gentle and extra efficient Black Is White Hydrosonic toothbrush and ingenious Black Is White activated carbon toothpaste.

With sinks available on stand, delegates were able to witness first hand the unique qualities of the products and the benefits that they pose to patients. quality French or Japanese steel, tungsten carbide tips from Serrations Ltd and all are available with optional titanium coating.

The company is unique in the marketplace in offering industry-leading warranties of between two and seven years on instruments in the Anaqa range.

Fast establishing itself as a pioneering brand in the surgical instruments market, ISFY is also known for its attention to detail, such as providing a choice of finishes for its instruments. The latest option, soon to launch, is a black finished range.

For more information on ISFY dental instruments, visit www.isfy.co.uk.

Other adjuncts in demand at the show were the range of interdental brushes, including CPS prime, CPS perio, CPS soft implant, CPS regular and CPS strong and implant.

A selection of manual toothbrushes was also available, with the special edition models proving to be a particular hit with professionals perusing the stand.

Did you miss the BDIA Dental Showcase 2016 and want to know more about the safe, gentle and effective products available from Curaprox? Then contact the team today. Call 01480862084 or visit www.curaprox.co.uk.

\section{Award winning imaging systems}

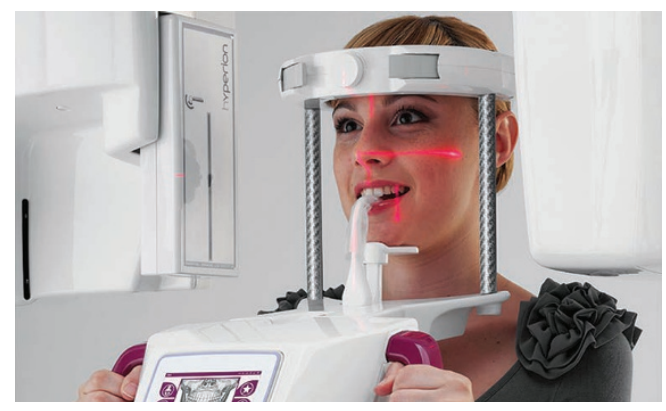

In 2015, the Hyperion X5 from MyRay was awarded the 2015 Red Dot Design Award for Product Design, proving itself to be one of the world's leading panoramic imaging systems in the field of radiology and diagnostics.

Refined, compact and easy to install, the Hyperion X5 is the smallest digital imager in the world, which is ideal for practices looking to maximise space.

The MyRay innovation is also incredibly easy to use thanks to its intuitive interface, virtual control panel and Morphology Recognition Technology, allowing you to make an instant diagnosis in just a few, simple steps.

The most innovative feature, however, is QuickPan, which reduces both exposure time and radiation dose.

Dedicated to providing imaging solutions that streamline workflows, improve performance and protect patients, MyRay produces other leading products such as the Hyperion X9 2D and 3D panoramic imaging system - which also won the Red Dot Award in 2013 - the C-U2 HD Camera and RXDC Hypersphere+ X-ray unit.

To find out more on these leading products, contact RPA Dental today. www.dental-equipment.co.uk

\section{Raising awareness of tooth wear and dentine hypersensitivity}

GSK is leading a campaign to raise awareness among dentists, DCPs and patients about two common conditions: erosive tooth wear and dentine hypersensitivity (DH).

Seventy-seven percent of British adults exhibit signs of tooth wear. ${ }^{1}$ You can now download the GSK BEWE app from the App Store for a comprehensive guide to erosive tooth wear diagnosis. Recommend Pronamel for daily protection from the effects of erosive tooth wear.
Dentine hypersensitivity is also widespread. $41.9 \%$ of adults have experienced it ${ }^{2}$ and over

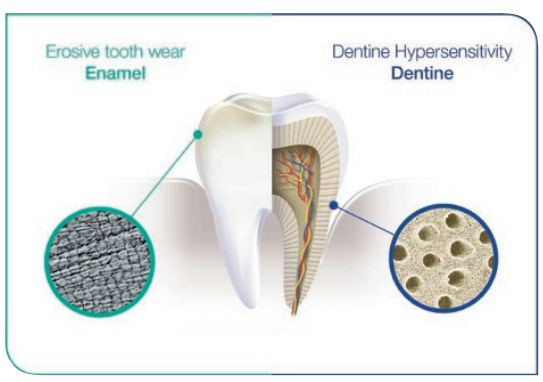

$70 \%$ of sufferers consider the sensations to take pleasure out of eating and drinking.3 Recommend Sensodyne Repair \& Protect for daily repair from $\mathrm{DH}$.

For more information on these conditions and other CPD materials, visit: https:// www.gsk-dentalprofessionals.co.uk/.

1 Disease and related disorders - a report from the Adult Dental Health Survey 2009. The Information Centre for health and social care, 2011

2 Addy M. Int Dent J 2002; 52: 367-375.

3. GSK Data on File RH02026. 